\title{
Departamento de Puericultura e Pediatria
}

\author{
José Romano Santoro \\ Docente. Aposentado. Faculdade de Medicina de Ribeirão Preto - USP.
}

$\mathrm{N}^{\circ}$ início de 1956, aceitando o convite do Prof. Zeferino Vaz, diretor da então recém-criada Faculdade de Medicina de Ribeirão Preto, o Prof. Jacob Renato Woiski organizou o Departamento de Puericultura e Pediatria. Com espírito inovador, propôs alterações em posições tradicionais da estrutura curricular, vigente na época, no ensino médico, com relação à Pediatria, estabeleceu 4 pontos básicos e organizou o ensino da Pediatria na nova faculdade:

1- A Pediatria deveria estar integrada ao ensino das outras matérias do currículo, merecendo maior destaque do que até aqui vinha tendo, mas sem o objetivo imediato da formação de especialistas. Deveria contribuir para a formação médica, revelando ao estudante os aspectos desta fase da evolução humana e dos reflexos na vida adulta. O programa de Pediatria, então elaborado, atendia a esta proposta.

2- A Pediatria deveria contribuir, principalmente, para o desenvolvimento da mentalidade da medicina preventiva, sem, contudo, descurar do ensino da medicina curativa.

3- A Pediatria deveria incutir no espírito do estudante a idéia da medicina integral, interpretando os casos concretos à luz de todos os fatores que pudessem ter influenciado sua determinação e sua evolução.

4- A Pediatria deveria merecer o tratamento de matéria básica do ciclo clínico.

Em relatório apresentado ao V Congresso Panamericano de Pediatria, em Lima, Peru, em 1957, escreveu o Prof. Woiski: “...A Pediatria não pode ser considerada como uma única especialidade. Ela é um conjunto de especialidades que abrange toda a medicina na infância. Ainda mais, a Pediatria, nos seus aspectos mais comuns e mais gerais, deve ser bagagem cultural de todos aqueles que se formam em medicina".

Esses 4 pontos básicos definiam a posição inovadora para a Pediatria na Faculdade de Medicina.

No início da vida do Departamento de Pediatria, solenidade marcante foi a aula inaugural do curso, em março de 1956, dada pelo Prof. Pedro de Alcântara, então catedrático de Pediatria da Faculdade de Medicina da Universidade de São Paulo, em São Paulo, com quem o Prof. Woiski havia trabalhado e, depois, substituído no Departamento de Pediatria da Escola Paulista de Medicina. A sessão solene foi presidida pelo Diretor da Faculdade, Prof. Zeferino Vaz e se realizou no então antigo "teatro", localizado nos fundos do prédio central da Faculdade de Medicina, local que, anos mais tarde, foi reformado e ocupado por seções administrativas da faculdade e por laboratórios.

\section{O INÍCIO DA VIDA DO DEPARTAMENTO: ADAPTAÇÕES E IMPROVISAÇÕES}

Em seu memorial apresentado, em 1966, ao concurso para a cátedra de Pediatria, em Ribeirão Preto, o Prof. Woiski relata o início da vida do departamento. As disponibilidades de espaço eram pequenas, exigindo adaptações e, também, improvisações. "No início do curso, diz o Prof. Woiski, contávamos só com o ambulatório localizado no primeiro prédio onde funcionou a Faculdade, na rua Visconde de Inhaúma, ao lado da Catedral (Figura 1), hoje demolido. Tínha- 




Foto 1: Primeiro prédio onde funcionou a FMRP-USP, na Rua Visconde de Inhauma, ao lado da Catedral.

mos, a minha secretaria, 2 salas para consultas com 2 mesas cada e 1 sala de aula na parte da frente com capacidade para mais ou menos 20 alunos. Ali atendíamos às tardes, nas segundas, quartas e sextas-feiras, de 12 às 16 horas. Pela exigüidade de espaço, 2 ou 3 alunos ficavam em cada mesa, orientados pelos assistentes. Na sala de aula, ficava eu com um grupo de 10 ou 12 alunos discutindo um caso. Das 16 às 17 horas reuniam-se todos na sala de aula para discutir os problemas observados no dia". Como a Faculdade ainda não tinha hospital próprio, "conseguimos permissão para, pela manhã, examinarmos e discutirmos os casos internados na Enfermaria de Pediatria da Santa Casa de Ribeirão Preto. Em instalações muito precárias, havia só crianças acima de 1 ano com processos, em geral prolongados de diarréia e desnutrição. Só podíamos examina-las e discutir os achados, sem acesso ao tratamento e conduta a tomar. De qualquer forma, isto vinha dar boa prática aos alunos".

\section{O HOSPITAL DAS CLÍNICAS}

Continua o Prof. Woiski em seu depoimento histórico: "Só no segundo semestre de 1956, pelos es- forços do Dr. Paulo Gomes Romeu na instalação do Hospital Maternidade Sinhá Junqueira, (transformado no Hospital das Clínicas da Faculdade) graças à colaboração do Dr. Waldemar Pessoa, conselheiro da Fundação "Cel. Quito Junqueira" que era a responsável pela construção do Hospital Maternidade "Sinhá Junqueira", passamos a ter 3 enfermarias com total de 12 leitos, no $1^{\text {o. }}$ andar do novo Hospital. Ao mesmo tempo obtivemos, também, 12 a 16 berços para o berçário". Realmente, início difícil. Por esta razão, as doações eram importantes. Em seu depoimento, o Prof. Woiski afirma que: “....em seu início o Departamento recebeu dotação da Fundação Rockefeller, dos Estados Unidos, tornando possível a aquisição dos primeiros equipamentos (projetor de slides, craveiras para enfermaria e ambulatório). Depois, a Fundação de Pesquisas Médicas de Ribeirão Preto (FUPEME), criada naquela ocasião e tendo à frente o Dr. Oswaldo Scatena, concedeu dotações à Faculdade o que permitiu novas aquisições e início das primeiras pesquisas. No decorrer dos anos seguintes, a Companhia Nestlé, em várias oportunidades, fez também doações importantes de equipamentos de laboratório ao Departamento". 
Já nos primeiros anos de funcionamento do $\mathrm{HC}$, começaram as reformas para melhor atender às necessidades não só administrativas, mas, também, de assistência e de ensino. Basta dizer que a primeira sala destinada às reuniões clínicas e clinicopatológicas, reunindo professores e alunos de várias séries, ficava logo à entrada do Hospital das Clínicas e tinha mais ou menos 60 metros quadrados. E era a única. Assim, por essa e outras razões, nova construção se inicia no terreno de fundo do Hospital das Clínicas, na rua Quintino Bocaiúva, com 6 andares. Na parte térrea do novo prédio, foi construído, também, anfiteatro com mais de 200 lugares e, ainda, espaço para todos os ambulatórios. O Departamento de Pediatria passou a ocupar o $3^{\circ}$. andar, compreendendo sala para a chefia, sala para os assistentes, sala para reuniões, enfermarias com, mais ou menos, 30 leitos e o berçário. Mas, ainda pela exigüidade de espaço, os ambulatórios de Pediatria funcionavam somente às terças e quintasfeiras às tardes, das 14 às $17 \mathrm{~h}$. Outros departamentos também necessitavam de mais espaço. Por isso, as reformas continuaram. Novos ambulatórios são, então, construídos no terreno do antigo seminário, localizado no quarteirão delimitado pelas ruas Bernardino de Campos, Rui Barbosa, Sete de Setembro e Garibaldi, ao lado do Hospital das Clínicas, adquirido pelo Governo do Estado. Ali foi levantada construção emergencial, para abrigar os ambulatórios do HC. Eram os chamados ambulatórios das Mangueiras, em virtude das várias árvores dessa espécie ali existentes. Nessa ocasião, os ambulatórios de Pediatria passaram a funcionar diariamente, nos 2 períodos do dia. O prédio do antigo seminário foi, pelo menos parcialmente, ocupado por alguns departamentos e pela administração do HC. Mas, em 1991, pela insegurança que apresentava, foi decidida a demolição do velho prédio. Muitos anos depois, na primeira metade da década de 80 , foi decidida a ocupação do referido quarteirão com um projeto avançado, que resultou em um moderno Centro de Convenções a serviço da comunidade.

A construção do anexo ao Hospital das Clínicas, na rua Quintino Bocaiúva, anteriormente referido, além de dar instalações mais amplas para o Departamento de Pediatria e também para outros, deu, ainda espaço, relativamente amplo, para que a Pediatria tivesse, em todo $06^{\circ}$ andar, seu próprio laboratório de microtécnicas que, antes, funcionava em pequeno espaço do Laboratório Central do Hospital, no $2^{\circ}$ andar.

No final da década de 60 , decidiu-se construir, na Fazenda Monte Alegre, nas imediações do prédio
Central da Faculdade de Medicina, um novo Hospital das Clínicas. A construção foi iniciada, porém paralisada por vários anos e, depois, retomada, sendo inauguradas as novas instalações em 1978. O Departamento de Pediatria se instalou em todo o $7^{\circ}$ andar dos 2 blocos que formam o conjunto do prédio. As enfermarias estão no bloco maior e a administração, a biblioteca, as salas de docentes, salas para aula e de reuniões com alunos da graduação e da pós-graduação ficam no bloco menor. Somente o berçário não ficou no $7^{\circ}$ andar, mas foi instalado ao lado do Centro Obstétrico, localizado na parte térrea, e no $8^{\circ}$ - andar, onde foi instalado o alojamento conjunto, 2 enfermarias para recém-nascidos a termo e 1 para pré-termos.

\section{O INDIGENTE}

A Pediatria e todos os departamentos clínicos e cirúrgicos do Hospital das Clínicas, durante vários anos, receberam e trataram indigentes, isto é, pessoas muito carentes e sem assistência médica previdenciária. Esse atendimento era feito, anteriormente, pelas Santas Casas de Misericórdia. Aqui em Ribeirão Preto, com a criação da Faculdade de Medicina e construção do Hospital das Clínicas, os indigentes passaram a ser atendidos também pelo Hospital das Clínicas, embora a Santa Casa de Misericórdia local continuasse o seu atendimento. $\mathrm{O}$ atendimento ao indigente permitia o trabalho docente assistencial e de pesquisa da Faculdade de Medicina nos 3 níveis de atendimento, primário, secundário e terciário e beneficiava a classe social menos favorecida.

No Hospital das Clínicas, o rigor do atendimento somente ao indigente, era aceito com restrições pelos docentes. Criou-se, então, uma justificativa para ser possível o atendimento a outras pessoas, não indigentes, sem ferir as normas do hospital: era o atendimento por interesse científico. $\mathrm{O}$ docente podia solicitar o registro, alegando esse motivo: interesse científico. O paciente, por sua vez, devia concordar com a rotina dos procedimentos do hospital-escola. Esses procedimentos são mantidos até hoje. Cada paciente conta seus problemas na primeira consulta e, depois, é solicitado pelos novos estagiários (médicos residentes, internos e alunos) a repetir suas histórias relatadas à internação. Por outro lado, as discussões, quando se faziam em torno do leito, eram ouvidas pelos pacientes, que acabavam memorizando diagnósticos, condutas e até previsão de alta. A Pediatria estava dentro de tal contexto. Muitas crianças, as maiores, sabiam, 
então, dizer aos novos estudantes ou aos residentes que chegavam o problema que tinham. De tanto ouvir, era natural que soubessem dizer muito bem seus problemas. Uma criança, por exemplo, que permanecia internada por questão social séria, sabia explicar que apresentava "uma estenose cáustica do esôfago por ingestão acidental de soda cáustica". Numa visita diária que os estagiários da Pediatria faziam aos internados nas enfermarias, um garoto dos seus 8 ou 9 anos, internado por problemas nutricional e gastrointestinal, ouviu a discussão. Terminada esta, quando todos se retiravam, chamou o responsável pela enfermaria e perguntou: "Oh tio (querendo exprimir tristeza), agora que eu estou comendo carne, o senhor vai me dar alta?" Muitas histórias, tristes histórias...

Nas décadas de 50 e 60, o atendimento à população trabalhadora era feito pelo INPS. Alguns sindicatos tinham seus próprios postos de atendimento médico, como os bancários, os comerciários, os industriários e outros. Depois veio INAMPS, que assumiu todo esse atendimento e os sindicatos fecharam seus postos. No Hospital das Clínicas, o rigor do atendimento somente ao indigente era aceito com restrições pelos docentes.

O respeito e o agradecimento ao indigente, nesse período, nunca foram esquecidos. Ao contrário, eram sempre lembrados, todos os anos, nos convites de formatura, onde os doutorandos davam especial destaque à homenagem de agradecimento ao indigente. E é este, também, o objetivo desta referência histórica, aqui feita: uma homenagem ao indigente das primeiras décadas de funcionamento do Hospital das Clínicas. Com a implantação do Sistema Único de Saúde, no final da década de 80 , a saúde passou a ser direito de todos, indistintamente, estendendo-se, assim, a todos o atendimento ambulatorial, hospitalar e medicamentoso.

\section{TEMPO INTEGRAL COM DEDICAÇÃO EXCLUSIVA - O PRIMEIRO CORPO DOCENTE DO DEPARTAMENTO DE PEDIATRIA}

Na organização da nova Faculdade de Medicina, o Prof. Zeferino Vaz inovou, exigindo que todo o pessoal docente fosse contratado em tempo integral, com dedicação exclusiva. Foi a primeira Escola de Medicina da América do Sul que adotou essa medida.

Em 1956, foram contratados os primeiros assistentes, convidados pelo Prof. Woiski. Assim, passaram a trabalhar com ele, vindos da Escola Paulista de Medicina, Olívio Paulus Junior, Gilberto Arantes, Abrão Berezim e Luiz Scatena. Também veio de São Paulo para ser o primeiro residente do novo departamento, Norberto de Oliveira, recém-formado pela Escola Paulista de Medicina. Após um ano de residência, também foi contratado assistente. Com a formatura da $1^{\text {a }}$. turma de médicos, em 1957, João Romera, então recém-formado, tornava-se um dos residente e depois assistente. No ano seguinte, em 1958, Carlos Elíseo de Castro Corrêa formava-se, e se tornava residente e depois assistente. Estava, assim, formada a primeira equipe de assistentes do Departamento de Pediatria. Entretanto, durante o ano de 1961, com exceção de Carlos Elíseo Castro Corrêa, todos os demais assistentes foram, um a um, solicitando demissão. Assim, já no final de 1961, o Prof. Woiski teve que organizar novo corpo docente. Convida, então, para serem seus novos assistentes, os residentes do ano. Todos aceitaram e foram contratados no início de 1962. Foram eles: Edgard Rolando, Luiz Gonzaga Faggioni, Luiz Carlos Raya e Sylvia Evelyn Hering. Também foi convidado e contratado, na mesma ocasião, José Romano Santoro que era assistente do Departamento de Medicina Legal e do Trabalho, mas que estava fazendo estágio, em 1961, na Pediatria. Formouse, então, o $2^{\circ}$ corpo docente do departamento. Outros ex-alunos e ex-residentes foram contratados a partir de 1964. Destacamos aqui, apenas Edgard Achê, Plínio Aidar Paiva e Maria do Rosário Leme Brasil. Os 2 primeiros solicitaram demissão alguns anos depois. A Dra. Maria do Rosário, chamada afetivamente de Dra. Daia, qualificou-se em mestrado e doutorado, desenvolveu, com o Dr. Collares, a Gastroenterologia e a Nutrição, mantendo, no ambulatório, atendimento aos pacientes recuperados da desnutrição. Vítima de insidiosa doença, faleceu em 1981.

\section{ENSINO MÉDICO EM COMUNIDADES}

\subsection{Ambulatório Rural na Fazenda Iracema e Ambulatório na Cidade de Cássia dos Co- queiros}

Em 1955, quando a $1^{\text {a. }}$ turma de estudantes da Faculdade de Medicina iniciou os chamados cursos de aplicação, ganhou força a proposta que os professores desses cursos vinham discutindo sobre o ensino prático, também fora do Hospital das Clínicas, em comunidades. Todos aderiram à idéia, pioneira no ensino médico, no Brasil. A bem da verdade, o Prof. Zeferino Vaz, ao planejar, de modo geral, o ensino na nova 


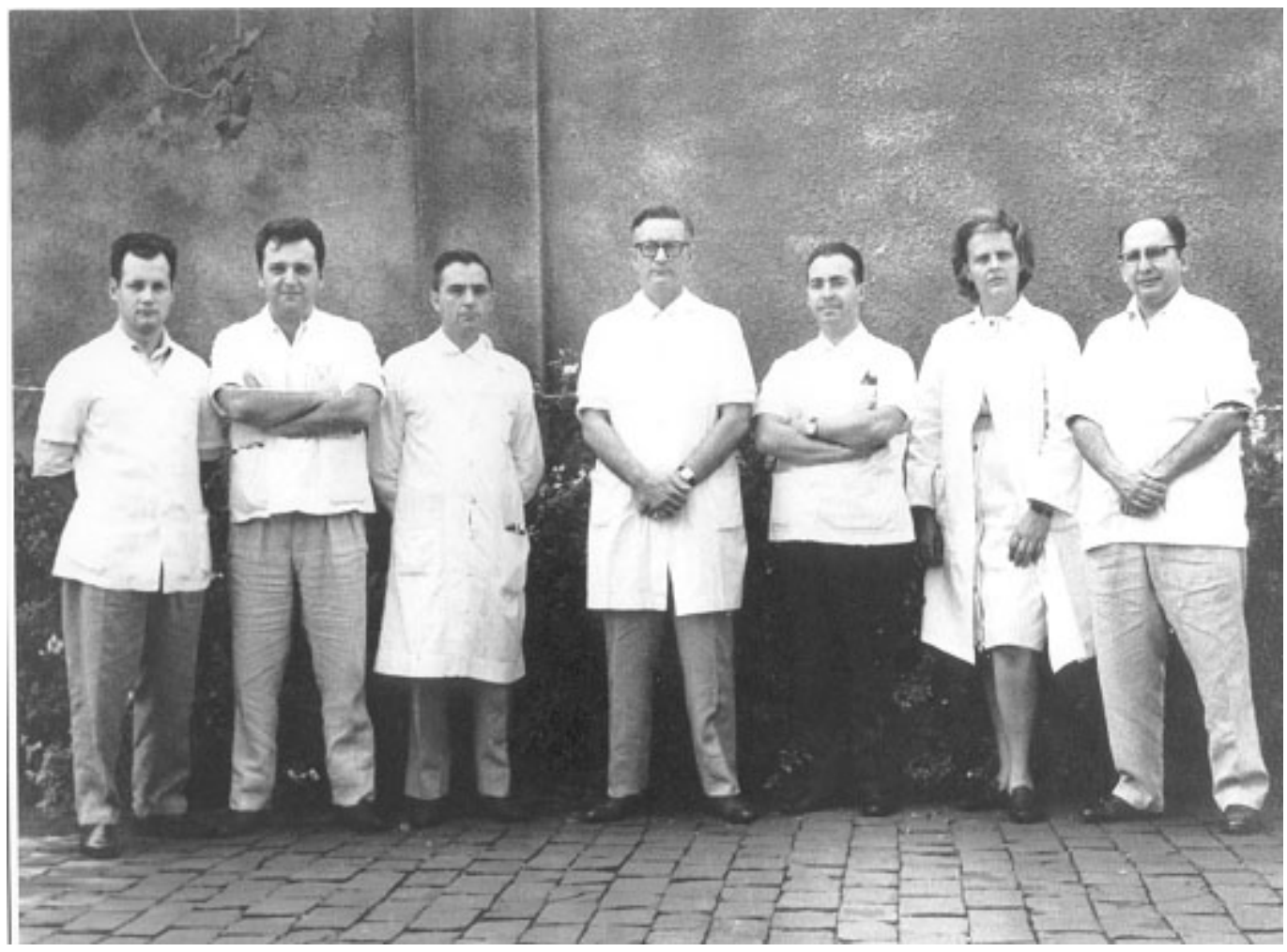

Foto 2: Pátio do Hospital das Clínicas - cidade - em 1963. Da esquerda para a direita Professores Edgard Rolando, Luiz Gonzaga Faggioni, José Romano Santoro, Jacob Renato Woiski, Carlos Eliseo Castro Correa, Sylvia Evelyn Hering e Luiz Carlos Raya.

faculdade, desejava levar os alunos para fora dos muros acadêmicos, na comunidade, através de um Centro de Saúde, que seria criado. Essa idéia não chegou a se concretizar. Mas, com a aprovação do ensino em comunidades, 2 áreas foram, então, escolhidas e os serviços instalados. Uma, na Fazenda Iracema, do Dr. Thomaz Alberto Wathelly, onde funcionou o ambulatório rural para adultos e crianças. A outra área foi instalada na cidade de Cássia dos Coqueiros, onde já havia atendimento a pacientes portadores da moléstia de Chagas, pertencentes ao programa de pesquisa, desenvolvido pelo Prof. José Lima Pedreira de Freitas, desde a década de 40 quando era assistente do Departamento de Parasitologia da Faculdade de Medicina de São Paulo. O Prof. Pedreira de Freitas, em meados da década de 50, tinha aceito o convite para trabalhar no Departamento de Parasitologia da Faculdade de Ribeirão Preto e já estava aqui trabalhando, quando foi convidado pelo Prof. Zeferino Vaz para organizar o Departamento de Medicina Preventiva da nova faculdade O Prof. Pedreira de Freitas aderiu ao ensino extramural, em comunidade, e ofereceu as instalações existentes em Cássia dos Coqueiros. O novo serviço ambulatorial multidisciplinar foi instalado. A Pediatria participou das 2 novas áreas de assistência/ ensino.

\subsection{Ambulatório na Usina São Martinho}

O ensino médico em comunidades havia entusiasmado o Prof. Woiski. No final da década de 60, mais precisamente em 1968, o Prof. Woiski, depois de entendimentos com o Dr. Orlando Ometto, diretor-presidente da Usina São Martinho, de Açúcar e Álcool, S/A, do município de Pradópolis, instalou ambulatório de Pediatria na usina, dando ênfase à Puericultura. $\mathrm{O}$ ambulatório funcionava às terças e quintas-feiras, às tardes, com alunos do $5^{\circ}$ ano e 1 docente. Os alunos demonstravam grande interesse e aproveitamento. Quando surgiu a primeira vacina contra sarampo, o Laboratório Wellcome, da Inglaterra, doou lote de vacinas ao departamento e cerca de 400 crianças foram vacinadas na usina. Diariamente, as crianças eram observadas, durante 15 dias, para serem registradas as reações que pudessem surgir com a vacina. Várias crianças apresentaram febre baixa e, destas, algumas tiveram exantema. 


\subsection{Centro Médico Social Comunitário de Vila Lobato}

Em 1969, após entendimentos com o então Secretário de Saúde da Prefeitura Municipal de Ribeirão Preto, Dr. Antônio Duarte Nogueira, ex-aluno de nossa faculdade, o Prof. Woiski obteve o importante apoio do Prefeito Municipal de Ribeirão Preto, Dr. Welson Gasparini, na construção de um centro médico em bairro carente da cidade. O bairro escolhido foi o de Vila Lobato, na ocasião, periférico, com inúmeros casebres e, praticamente, sem saneamento básico. Assim, foi construído e equipado pela prefeitura o Centro Médico Social Comunitário de Vila Lobato, com a aprovação da Faculdade de Medicina e do Hospital das Clínicas, que se tornaram referência para o novo centro. A Escola de Enfermagem de Ribeirão Preto, com a diretora Profa. Glete de Alcântara, aderiu e participou do projeto. O atendimento era multidisciplinar: Clínica Médica, Pediatria, Ginecologia e Obstetrícia, Medicina Social e Psiquiatria. Participavam do atendimento os docentes de cada área, os residentes dos departamentos e alunos em estágio na área. A Escola de Enfermagem fazia todo o atendimento de enfermagem, com docentes e alunas em estágio no referido centro médico.

Á inauguração, tomou posse, como diretor, o Prof. Júlio Cesar Daneluzzi, da Pediatria, que vem permanecendo no cargo, sem interrupção, até hoje.

Com o passar do tempo e as naturais mudanças nos objetivos de ensino, assistência e pesquisa, alguns departamentos deixaram Vila Lobato. Hoje, permanecem apenas os Departamentos de Pediatria e de Ginecologia e Obstetrícia. Ambos vêm cumprindo o compromisso inicial, assumido, de assistência à mãe e à criança, dentro da filosofia da Medicina Social. Particularmente, o ensino tem sido beneficiado, porque a assistência tem sido feita dentro e fora dali e não se limita aos instantes da consulta. Vai muito além, nas visitas domiciliares, nas reuniões de educação para a saúde, nas reuniões com as gestantes, para que conheçam peculiaridades da gestação e do parto, nas aulas de corte e costura, onde preparam os enxovais dos seus bebês, nas aulas de pintura em tecido, nas reuniões com adolescentes, etc., uma verdadeira clínica de família.

Há, na história de Vila Lobato, um fato que precisa ser lembrado. Estávamos na época da anistia política, que o governo militar brasileiro vinha concedendo aos perseguidos políticos cassados. O Prof. Hélio Lourenço de Oliveira, chefe do Departamento de Clínica Médica que, na época da revolução, era reitor da Universidade de São Paulo e foi injustamente cassado e afastado dela, estava sendo anistiado e retornava ao seu cargo de professor universitário. Queria voltar a trabalhar. Era professor no Departamento de Clínica Médica, que ele organizara, mas desejava mudar o rumo de suas atividades de professor e pesquisador. Muito provavelmente, pelas antigas ligações, até históricas, mantidas com o Prof. Woiski e o Departamento de Pediatria, o Prof. Hélio procurou o Prof. Santoro, então, responsável pelo Setor de Pediatria, manifestando seu desejo de desenvolver trabalho médico comunitário. Na época, na Faculdade de Medicina havia 2 áreas em que a atividade docente assistencial em comunidade funcionava em Ribeirão Preto: O Centro Médico de Vila Lobato e o Centro de Saúde-Escola, do Departamento de Medicina Social. O Prof. Santoro, então, marcou reunião, no Centro de Vila Lobato, com o Prof. Júlio e convidou os Profs. Nagib e Juan, ambos da Medicina Social, para participarem. Na reunião, os 2 serviços foram colocados à disposição do Prof. Hélio. Depois de, cuidadosamente, justificar, escolheu Vila Lobato. E expôs seu plano: desejava ver os pais das crianças que iniciavam o atendimento na Puericultura, independentemente de problemas de saúde. Assim, todos seriam convidados a comparecer, seriam entrevistados e examinados. O trabalho era inovador e começou logo em seguida. Os alunos do $4^{\circ}$. ano, em estágio na Puericultura em Vila Lobato, deviam preparar os prontuários, fazer os atendimentos aos pais das crianças e discutir, depois, com o Prof. Hélio toda a observação clínica. Os detalhes eram muito importantes, porque os examinados se consideravam pessoas saudáveis. Os alunos, logo que começaram a fazer os atendimentos, se entusiasmaram com o novo trabalho, tal a riqueza de conhecimentos que recebiam com a prática clínica e com as discussões feitas com o Prof. Hélio. Apesar de "saudáveis", muitos problemas foram detectados e resolvidos. No ano seguinte, o Prof. Hélio, já doente, assumia o cargo de Diretor da Faculdade de Medicina, para o qual tinha sido eleito por aclamação da Congregação e foi obrigado a se afastar do atendimento em Vila Lobato. Infelizmente, não teve substituto. Os alunos lamentaram. Esse novo tipo de atendimento dava início a importante mudança na atitude do médico e do serviço em relação à comunidade, apesar de o atendimento em Vila Lobato ter o caráter social-comunitário. Estava mostrando a importância da reaproximação do médico à família do paciente. 
O Centro Médico Social Comunitário de Vila Lobato tem sido muito útil ao ensino, à pesquisa e à assistência. É importante dizer que muitas dissertações de mestrado e teses de doutorado têm sido feitas com a utilização dos prontuários ali existentes.

\subsection{Pediatria Social - Josiah Macy Jr. Foundation}

No decorrer de 1969, outro entendimento importante para o ensino, pesquisa e assistência em Pediatria foi o realizado pelo Prof. Woiski com a Josiah Macy Jr. Foundation, de Nova York, para desenvolver programa de Pediatria Social. Com esse programa, o departamento passou a oferecer estágio a médicos recém-formados em escolas do Norte e Nordeste do país, mas, logo depois, estendeu-se, também, a médicos formados em escolas do Sul. O entendimento com a fundação americana foi importante, por causa da dotação concedida, mas, o mais importante foi o desenvolvimento do atendimento médico dentro de novo conceito, o do social, humanizando o atendimento através de relação médico-paciente, médicofamiliares ou médico-mãe do paciente, dentro do espírito de reciprocidade, facilitando o entendimento da doença, o diagnóstico e o tratamento. A Pediatria Social e a Medicina Social vieram sugerir ao médico essa nova atitude no atendimento. Por isso é que se diz que Pediatria Social é atitude. Além disso, a Pediatria Social propôs um novo conceito, que considera a criança, em seu todo orgânico, psíquico e social, dentro do meio em que vive, dando, assim, valor à relação paciente e seus circunstantes e às condições de vida desse grupo.

O Departamento recebeu a dotação total anual da Macy até 1972, passando, depois, a receber apenas parte dela, dividindo o todo com o Departamento de Pediatria da Faculdade de Medicina da Santa Casa de São Paulo, para onde o Prof. Woiski fora trabalhar, assumindo a chefia do Departamento de Pediatria daquela Faculdade, depois de aqui se aposentar, em 1971.

\subsection{Novas Áreas de Trabalho}

As dificuldades iniciais para o Departamento de Pediatria desenvolver suas atividades de assistência, ensino e pesquisa tiveram que ser, aos poucos, vencidas. A maior parte foi superada com a instalação do primeiro Hospital das Clínicas e dos centros comunitários. Para crescer, entretanto, dando maiores oportunidades de treinamento aos estudantes, residentes e docentes, o Prof. Woiski, depois de enten- dimentos com a Prefeitura Municipal de Ribeirão Preto, instalou, no prédio do Pronto-Socorro Municipal, o Pronto-Socorro Infantil com atendimentos ambulatoriais e de internação. Em poucos meses, com a aceitação pela comunidade e crescimento do novo serviço, todo o prédio passou a ser ocupado pelo ProntoSocorro Infantil. Funcionava $24 \mathrm{~h}$, em sistema de plantão permanente.

Outra nova área, aberta em 1968, foi a do Hospital Santa Lydia. Era um hospital mantido pela Fundação Ribeiro Pinto e se destinava ao atendimento de crianças com problemas ortopédicos. O departamento assumiu o atendimento, transformando-o em hospital geral, infantil. Em certa época, desenvolveu-se lá a importante área de tratamento das moléstias infecciosas.

Tanto o Pronto-Socorro Infantil como o Hospital Santa Lydia foram assumidos pelo departamento até 1978, retirando-se em seguida, em virtude da inauguração do novo Hospital das Clinicas, no Campus Universitário e da transformação do antigo Hospital das Clínicas da cidade em Unidade de Emergência.

\subsection{Centro de Saúde-Escola}

Outra área importante para o Departamento de Pediatria foi a do Centro de Saúde-Escola, localizado no bairro do Ipiranga e coordenado pelo Departamento de Medicina Social. Poucos sabem, mas o Centro de Saúde-Escola faz parte da história do Departamento de Pediatria. Em 1977, um grupo de docentes do departamento, ligados ao atendimento em comunidade, entre eles os Drs. Santoro, Barbieri, Ricco, Júlio e Barros, decidiram apresentar à Secretaria de Saúde do Estado um programa de saúde materna e infantil para a cidade de Ribeirão Preto. Era um plano ambicioso, porque visava utilizar todos os postos de saúde da cidade, pertencentes à rede pública estadual e ainda instalar outros em áreas populosas, não assistidas, com o objetivo de dar cobertura ampla ao atendimento materno e infantil, aumentando, assim, as possibilidades de atendimento e evitando concentração em alguns postos, como era freqüente. O programa proposto era de atendimento às gestantes com pré-natal e assistência ao parto e, depois, atendimento à mãe e à criança, logo após o nascimento e durante seu crescimento, pela Puericultura. Durante todo esse período, a mãe recebia educação para a saúde. O programa foi posto no papel e levado em mãos ao Prof. Walter Leser, na época, Secretário Estadual da Saúde, que ouviu atentamente e manifestou-se favorável a um 
trabalho dessa natureza, de assistência médica e educacional às mães e a seus filhos, nas próprias comunidades. Prometeu estudar a proposta com seus assessores. Algumas semanas depois, o Prof. Santoro recebeu convite para reunião que seria realizada na Diretoria Regional de Saúde com a presença de um assessor do Secretário da Saúde e do Prof. Nagib Haddad, chefe do Departamento de Medicina Social da nossa faculdade. Nessa reunião, o assessor do Secretário da Saúde apresentou contra-proposta: a criação de um Centro de Saúde-Escola, nos moldes do que a Secretaria da Saúde havia criado e estava já funcionando em Botucatu, com a Faculdade de Medicina, num convênio entre a Secretaria e o Departamento de Medicina Social daquela faculdade. Assim, foi criado o Centro de Saúde-Escola, em Ribeirão Preto. O Departamento de Pediatria foi, então, convidado a participar e vem participando dos programas de atendimento com alunos, residentes e docentes. Considera importante essa participação docente-assistencial e de pesquisa.

\subsection{Centro Médico Social Comunitário de Pradópolis}

Nos últimos meses de 1971, dentro das propostas da Pediatria Social, o Departamento de Pediatria da Faculdade de Medicina de Ribeirão Preto aceitou o convite do Dr. Orlando Ometto, então Prefeito de Pradópolis e diretor da Usina São Martinho, de Açúcar e Álcool S/A, do mesmo município, para a Pediatria fazer, também, atendimentos médicos, pois a cidade estava sem médico fazia 2 anos. A oferta foi aceita como extensão do atendimento que era, já, feito na usina. Os atendimentos começaram e o interesse da população foi crescente a ponto de o prefeito propor a construção de pequeno hospital. À primeira vista, a proposta era tentadora, mas, conhecendo já a população e suas necessidades de saúde, o Departamento de Pediatria convenceu o prefeito de que o mais indicado para a comunidade seria ter um ambulatório, funcionando diariamente para crianças, adultos e gestantes, além de um programa continuado de educação para a saúde. As internações deviam continuar a ser feitas nos hospitais das cidades vizinhas. A proposta foi aceita e o prédio para o ambulatório foi construído e equipado. Até o término da construção, uma casa foi alugada e adaptada para o atendimento e moradia dos residentes que ali permaneciam durante 1 mês. Assim, surgiu o Centro Médico Social Comunitário de Pradópolis. O convênio com a Universidade de São
Paulo foi celebrado em 1974. Nessa época, a cidade, com 5 mil habitantes, já possuía excelente serviço de saneamento básico, pois todas as casas estavam ligadas às redes de água e esgoto. Mas, fato importante era que todo o esgoto, antes de ser drenado para o rio, era tratado em lagoas de oxidação, não poluindo o solo e os rios. Naquela época, eram pouquíssimos os municípios do Estado de São Paulo que possuíam serviço de saneamento básico daquele porte.

O convênio com a Prefeitura de Pradópolis vigorou até 1991, quando foi suspenso, em virtude da natural e necessária adesão da Prefeitura Municipal ao programa do Sistema Único de Saúde (SUS), do Ministério da Saúde. Uma das exigências do SUS era que a prefeitura não poderia ter convênios com outras entidades de saúde. Mas uma questão mais importante ainda era que, na programação do SUS não havia lugar para a Puericultura e isso, para o Departamento de Pediatria, foi inaceitável. Por tal razão, o convênio foi denunciado.

\section{CURSO CONTINUADO DE PEDIATRIA}

Outra inovação, também pioneira no ensino médico aqui no Brasil, foi a organização, em 1963, de um curso de atualização em Pediatria, aberto a todos os pediatras. Entusiasmado com o ensino da Pediatria, o Prof. Woiski considerava como fundamental a atualização continuada dos pediatras. Não a atualização periódica, de congressos, conferências, simpósios, mas a frequiente, sistemática, continuada. Da idéia à prática, a distância foi curta. Após alguns entendimentos rápidos, ao final de uma reunião para discussão de problemas clínicos de Pediatria e onde estavam presentes pediatras da região, foi criado o Curso Continuado de Pediatria, programado para ter reuniões mensais, aos sábados, ocupando os 2 períodos do dia. E assim foi feito. Vinham pediatras de cidades distantes como São José do Rio Preto, Barretos, Araçatuba, Votuporanga, Catanduva, Mirassol, Ibirá, São Carlos, Araraquara, Franca, alem de Batatais, Jaboticabal, São Simão, Pirassununga, Cravinhos e de outras mais próximas de Ribeirão Preto.

O Curso Continuado de Pediatria foi oficializado pela Universidade de São Paulo, em $1^{\circ}$ - de outubro de 1964, como Curso de Extensão Universitária e Divulgação Cultural. Durante os 37 anos de existência, o curso sofreu uma ou duas pequenas interrupções, foi re-programado e continua com o mesmo vigor do início até hoje. 
O saudosismo me impõe a citação de alguns pediatras que se tornaram familiares, pois estavam presentes na reunião de criação do curso e sempre estavam presentes nas reuniões e participavam, demonstrando muito interesse. O Prof. Woiski gostava muito deles. Eram pediatras de muitos anos, admiradores do Prof. Woiski e vinham, quase todos, de muito longe: Lineu de Alcântara Gil, Francisco Iglesias, Alcyr Costacurta, Nélvio Pala, Joaquim Alves Ferreira. Mas havia outros, também, familiares do departamento, exdocentes, como João Romera, Carlos Elíseo Castro Corrêa e ainda outros, como Degani, sempre muito sério, Normanha, festivo, e Pratinha ,seu amigo e colega de consultório. A citação de todos, agora, é impossível, infelizmente.

\section{CURSO DE PREPARAÇÃO DOCENTE}

Neste resumo histórico da vida do Departamento de Pediatria, estamos dando destaque aos muitos fatos considerados memoráveis e que foram, muitos deles, indiscutivelmente, marcados pelo pioneirismo. Foi o que aconteceu com mais este fato. Na organização dos departamentos, o Prof. Zeferino Vaz, Diretor da Faculdade, convidou professores, principalmente de São Paulo. Esses professores, naturalmente, trouxeram seus primeiros assistentes. Mas os alunos das primeiras turmas da FMRP-USP, que se destacavam e que demonstravam interesse pela carreira docente, eram convidados e contratados pelos vários departamentos. Assim ocorreu na Pediatria. O Prof. Woiski estava preocupado com a qualificação mais rápida dos seus docentes, todos ex-alunos da citada faculdade, introduzidos na carreira docente logo ao término da residência. Essa mesma preocupação era alimentada pelo Prof. Hélio Lourenço de Oliveira, chefe do Departamento de Clínica Médica que, embora tivesse vários docentes já qualificados, com doutoramento e livre-docência, vindos com ele de São Paulo, da mesma maneira, tinha já ex-alunos da nossa faculdade como assistentes. Assim, os Profs, Woiski e Hélio decidiram organizar um curso inovador de preparação docente. Em 1965, por iniciativa dos 2 professores, a Congregação da Faculdade aprovou o funcionamento de um novo curso, que não conferia título, mas dava ao aluno, em 1 ano, iniciação científica para o necessário desenvolvimento de sua qualificação. O curso era estruturado com uma disciplina compulsória denominada: Nutrição e Metabolismo: Metodologia Aplicada à Investigação de Problemas Clínicos. Além desta, havia 2 disciplinas complementares: Estatística e Laboratório. É bom dizer, fazendo justiça à história que, antes desse curso, havia funcionado, no ano anterior, outro somente de Estatística para docentes novos, ministrado pelo Prof. Dr. Geraldo Garcia Duarte, do Departamento de Medicina Preventiva.

Como relato histórico e pela relevância do fato, é importante apresentar aqui o programa da disciplina compulsória.

\section{I - Temas}

\section{A - Crescimento}

1 - Análise e crítica de curvas de crescimento resultantes de estudos "transversais" e "longitudinais". 2 - Crescimento global, crescimento segmentar e crescimento de órgãos; suas relações.

B - Composição do organismo

1 - Resultado de análise direta.

2 - Balanço metabólico: o método geral e seus resultados. Análise crítica.

3 - Interpretação de dados de balanço: Correlação de dados de balanços combinados.

C - Resultado do crescimento e da manutenção do desenvolvimento adulto: fatores genéticos, endócrino, nutricionais e metabólicos. Caracterização de suas anormalidades pelas curvas de crescimento e pelos dados de balanços metabólicos.

D - Equilíbrio dos líquidos em distintos compartimentos do organismo.

1 - Avaliação da água total e dos compartimentos extracelulares. Métodos.

2 - Anormalidades de equilíbrio dos líquidos do organismo: caracterização pelo balanço de água e de eletrólitos.

3 - Anormalidades da composição do líquido extracelular.

\section{II - Desenvolvimento}

Os temas foram desenvolvidos através de:

A - séries sistematizadas de observações clínicas;

$\mathrm{B}$ - métodos de laboratório aplicados à pesquisa clínica;

$\mathrm{C}$ - experimentos em animais;

D - seminários;

E - aulas teóricas ou conferências.

Os seminários destinavam-se à discussão ampla, tanto dos aspectos teóricos, apresentados em aulas ou em conferências, como dos resultados colhidos 
nos trabalhos práticos. Para esse fim, os seminários exigiam pesquisa bibliográfica, como atividade regular durante todo o curso.

O processo que tratou da inscrição dos candidatos ao curso teve o número 65.1.1006.17.3, de 1965.

Inscreveram-se 28 candidatos. Foram selecionados 14 os quais, logo em seguida, se matricularam. Eram todos instrutores (primeiro degrau da carreira docente) de vários departamentos da Faculdade. As aulas foram iniciadas em agosto de 1965 e foram até junho de 1966. Mas é justo e interessante lembrar que, antes desse curso, funcionou outro para docentes de Pediatria, com as mesmas preocupações de preparação docente, mas com ênfase em Estatística e foi ministrado pelo Prof. Geraldo Garcia Duarte, que pertencia ao então Departamento de Medicina Preventiva e se dedicava à estatística.

Foram os seguintes os matriculados:

1 - Willy Sarti - Departamento de Clínica Médica;

2 - Luiz Gonzaga Faggioni - Departamento de Pediatria;

3 - Carlos Elíseo Castro Corrêa - Departamento de Pediatria;

4 - José Romano Santoro - Departamento de Pediatria;

5 - Kanji Kamata - Departamento de Clínica Médica;

6 - Arnaldo Zanardi - Departamento de Ginecologia e Obstetrícia;

7 - Ulysses Garzela Meneghelli - Departamento de Clínica Médica;

8 - Luiz Carlos Raya - Departamento de Pediatria;

9 - Paulo Múcio Guimarães Pagnano - Departamento de Dermatologia;

10 - Akio Tanaka - Departamento de Cirurgia;

11 - Ana Maria Uthida Tanaka - Departamento de Dermatologia;

12 - Cláudio Tácito M. Escobar - Departamento de Cirurgia;

13 - Márcio S. Costa Pereira - Departamento de Cirurgia;

14 - Carlos Júlio Laure - Departamento de Bioquímica.

Razões de ordem universitária, envolvendo o Prof. Woiski e o Prof. Hélio, orientadores do curso, em atividades universitárias administrativas, não permitiram que o curso fosse, novamente, oferecido. Mas havia candidatos interessados.

É justo que se diga que o referido curso de qualificação docente foi precursor dos Cursos de Pósgraduação, instalados no Brasil pelo Ministério da Educação, em 1971.

\section{CURSO DE PÓS-GRAdUAÇÃ̃o}

Em 1971, com a instituição da Pós-graduação no Brasil, a Faculdade de Medicina de Ribeirão Preto aderiu ao novo programa. A Comissão de Pós-graduação, então formada, iniciou processo de divulgação e organização dos cursos nos diversos departamentos. O Dr. José Romano Santoro, que pertencia à referida comissão, foi encarregado de organizar o curso na área de Pediatria, em nível de mestrado e de doutorado e foi o primeiro coordenador do curso no Departamento de Pediatria. Atendendo às exigências legais, o processo do novo curso, depois de aprovado na Universidade, foi levado a Brasília, sendo o $1^{\circ}$. curso de Pós-graduação em Pediatria, nível de mestrado e doutorado aprovado pelo Ministério da Educação. $\mathrm{O} 1^{\circ}$. grau de Mestre foi atribuído ao então pós-graduando Salim Moysés Jorge, em 1973, hoje Prof. Titular do Departamento de Pediatria.

$\mathrm{Na}$ estrutura do novo curso havia 1 disciplina compulsória - Crescimento e Desenvolvimento - e 4 disciplinas opcionais, além de pré-requisitos para o curso. Com o decorrer do tempo, foram surgindo mudanças naturais e necessárias.

Até o presente, o Curso de Pós-graduação em Pediatria já graduou 158 mestres e 82 doutores.

No ano de 2002, estavam matriculados, em mestrado, 25 alunos e, em doutorado, 17 alunos.

É coordenadora do Curso de Pós-graduação a Profa. Dra. Marisa Márcia Mussi Pinhata e vice-coordenadora a Profa. Dra. Virgínia Paes Leme Ferriani.

\section{DEPARTAMENTO DE GINECOLOGIA, OBSTETRÍCIA E PEDIATRIA}

Com a aposentadoria do Prof. Woiski, em 1971, e com a reforma universitária, na mesma ocasião, o Departamento de Pediatria foi anexado ao Departamento de Ginecologia e Obstetrícia, formando o Departamento de Ginecologia, Obstetrícia e Pediatria. Nessa época, os docentes mais graduados da Pediatria eram doutores e não havia a estrutura necessária para que o Departamento de Pediatria continuasse existindo, com a saída do Prof. Woiski. A fusão, como outras, que também ocorreram em virtude da reforma, foram artificiais. E continuam sendo. Esta questão precisaria ser, cuidadosamente, examinada. $\mathrm{Na}$ Pediatria, mas também na Ginecologia e Obstetrícia, sempre houve desejo de separação das áreas e esta só pôde ocorrer, a julgar pelo mérito, em 1984, quando o Prof. Santoro, a partir de 1981, tornou-se professor 
titular. Então, o processo de subdivisão do Departamento de Ginecologia, Obstetrícia e Pediatria foi aprovado pelo departamento e, no mérito, pela Congregação da Faculdade e encaminhado ao Conselho Universitário onde, também, foi aprovado no mérito sendo, então, efetivada a separação por despacho do Reitor, em 1984. Estava, assim, iniciada nova fase na vida do Departamento de Pediatria. Em reunião realizada em 1984, com a presença de todos os docentes, foram eleitos para chefe e suplente de chefe, pelo período 4 anos, respectivamente, José Romano Santoro e Arthur Lopes Gonçalves. Também foi organizado o primeiro Conselho do Departamento, com docentes das categorias existentes. Mas uma decisão inédita foi tomada naquele momento, por aclamação de todos os presentes: o novo conselho, em suas reuniões ordinárias e extraordinárias, permitiria a presença de todos os docentes do Departamento de Pediatria. Assim tem sido até hoje.

Em 13 de maio de 1987, o Prof.Santoro solicitou aposentadoria, sendo substituído pelo suplente, Prof. Arthur que, logo, convocou eleições. As chefias que se seguiram a partir de maio de 1987, foram as seguintes:

- De maio de 1987 a maio de 1991 - Chefe: Prof. Arthur Lopes Gonçalves; Suplente: Prof. Salim Moysés Jorge.

- De maio de 1991 a maio de 1993 - Chefe: Prof. Marco Antônio Barbieri; Suplente: Prof. Arthur Lopes Gonçalves.

- De maio de 1993 a maio de 1995 - Chefe: Prof. Salim Moysés Jorge; Suplente Prof. Arthur Lopes Gonçalves.

- De junho de 1995 a junho de 1997 - Chefe: Prof. Francisco Eulógio Martinez; Suplente Prof. Rubens Garcia Ricco.

- De junho de 1997 a junho de 1999 - Chefe: Rubens Garcia Ricco e Suplentes Profs. Francisco Eulógio Martinez e Luiz Gonzaga Tone.

- De junho de 1999 a junho de 2001 - Chefe: Prof. Salim Moysés Jorge; Suplentes Profs. Luiz Gonzaga Tone e Marco Antônio Barbieri.

O corpo docente tem os seguintes professores e suas categorias:

Professores Titulares: Arthur Lopes Gonçalves, Marco Antônio Barbieri e Salim Moyses Jorge;

Professores Associados: Francisco Eulógio Martinez, Maria Inez Machado Fernandes e Rubens Garcia Ricco.

Professores Doutores: Fernando Carlos Soares, Heloisa Bettiol, João Antonio Granzotti, Júlio
Cesar Daneluzzi, Lívia Carvalho Galvão, Luiz Gonzaga Tone, Maria Célia Cervi, Maria Lúcia Ferlin, Maria Márcia Mussi Pinhata, Naul Motta de Souza, Palmira Cupo, Paulo Benedito Franco e Virgínia Paes Leme Ferriani

Há, ainda, docentes contratados pela FAEPA (Fundação de Amparo ao Ensino, Pesquisa e Assistência). São os seguintes, os professores doutores: Carlos Eduardo Martinelli Junior, Luiz Antonio Del Ciampo e Luiza Karla de Paula Arruda e a mestra Ana Paula Carvalho Panzeri Carlotti.

\section{CENTRO DE ESTUDO E PESQUISA PE- DIÁTRICA (CEPP)}

O CEPP não faz parte da estrutura do Departamento de Pediatria. É totalmente independente. Tem vida própria. Mas nasceu na Pediatria e, por isso e com razão, faz parte de sua história. Um grupo de docentes se reuniu na Pediatria, atendendo ao convite do Prof. Santoro, então responsável pelo setor de Pediatria, com a finalidade de discutir a proposta de criar um centro destinado a promover o estudo e a pesquisa em Pediatria. O estudo seria desenvolvido através de reuniões científicas programadas e a pesquisa, dependendo de recursos disponíveis, poderia ser financiada pelo CEPP pois este, como entidade jurídica, receberia doações e as aplicaria em pesquisa e em atividades de estudo. Foi, então, marcada a primeira reunião oficial para o dia 04 de fevereiro de 1972. Pelo seu valor histórico, a ata dessa reunião será transcrita a seguir: "Cópia da ata da primeira reunião do Centro de Estudo e Pesquisa Pediátrica - (CEPP). Aos 4 dias do mês de fevereiro de 1972, com a presença dos doutores Carlos Elysio Castro Corrêa, Arthur Lopes Gonçalves, Luiz Gonzaga Faggioni, Edgar Achê, Júlio Cesar Daneluzzi, Sylvia Evelyn Hering, Edgard Ferro Collares, Salim Moysés Jorge, Naul Motta de Souza, Edgard Rolando e José Romano Santoro, realizou-se em uma das salas do Departamento de Pediatria da Faculdade de Medicina de Ribeirão Preto, reunião para a fundação de uma sociedade científica que foi denominada de Centro de Estudo e Pesquisa Pediátrica (CEPP). O Dr. José Romano Santoro que apresentou a proposta aos presentes, frisou que a sociedade ora em organização não teria vínculo algum com qualquer sociedade ou Instituição, o que foi aceito. A seguir, foram escolhidos entre os presentes os doutores Júlio César Daneluzzi, José Romano Santoro, Edgard Rolando, Edgard Ferro Collares, 




Foto 3: Centro Médico Social Comunitário de Vila Lobato - 2001. Docentes do Departamento de Puericultura e Pediatria - DPP e Equipe Multiprofissional.

Foto 4: Hospital das Clínicas da Faculdade de Medicina de Ribeirão Preto da USP - Campus 2001. Docentes do DPP e Equipe Multiprofissional.
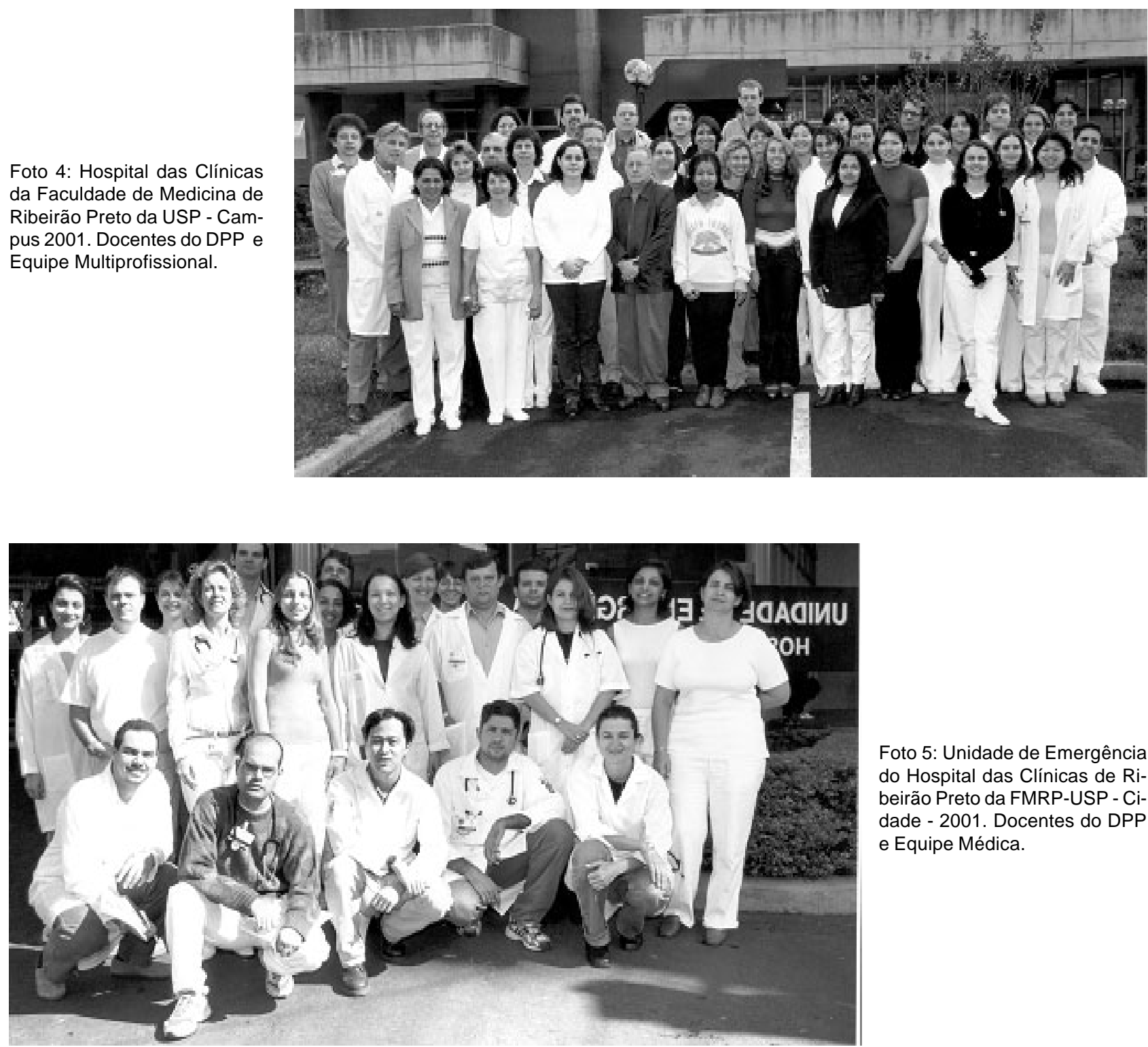

Foto 5: Unidade de Emergência do Hospital das Clínicas de Ribeirão Preto da FMRP-USP - Cidade - 2001. Docentes do DPP e Equipe Médica. 
Salim Moysés Jorge e Arthur Lopes Gonçalves para formar comissão encarregada de elaborar o Regulamento do Centro e convocar nova reunião para organização do Conselho Administrativo e Diretoria e apresentar o Regulamento no prazo de 10 dias. Não havendo mais nada para ser discutido encerrou-se a presente sessão sendo lavrada a presente ata por mim, José Romano Santoro, escrita e assinada por todos os presentes: (a-a) José Romano Santoro, Edgard Ferro Collares, Carlos Elysio Castro Corrêa, Edgard Rolando, Luiz Gonzaga Faggioni, Edgard Achê, Júlio César Daneluzzi, Arthur Lopes Gonçalves, Sylvia Evelyn Hering, Naul Motta de Souza, Salim Moysés Jorge. Datilografada por Ana Ribeiro em 19/5/73 Confere com o original. Ribeirão Preto, 20 de maio de 1973. Ass.: Dr. Arthur Lopes Gonçalves, Segundo Secretário em exercício do CEPP".

No dia 11 de fevereiro, foi realizada a segunda reunião, para a apresentação da proposta do regulamento da sociedade. A referida reunião foi realizada, o regulamento foi aprovado e, no final da reunião, foi marcada nova reunião para o dia 21 de fevereiro de 1972, para as primeiras deliberações e a formação da primeira diretoria, cuja constituição foi a seguinte: Presidente: Dr. José Romano Santoro; $1^{\circ}$ secretário: Dr. Edgard Rolando; $2^{\circ}$ secretário: Dr. Arthur Lopes Gonçalves; $1^{\circ}$ tesoureiro: Dra, Sylvia Evelyn Hering; $2^{\circ}$ tesoureiro: Edgard Ferro Collares.

O CEPP já completou 29 anos de vida, cumprindo seus objetivos de promover reuniões de estudo e divulgação científica ligadas à Pediatria além de dar apoio financeiro a trabalhos de pesquisa e viagens de seus associados para participarem de congressos e de outras reuniões científicas, com receitas provindas de doações. O Curso Continuado de Pediatria, por exemplo, vem sendo promovido pelo CEPP.

A atual diretoria da sociedade está assim constituída: Presidente: Dra. Marisa Márcia Mussi Pinhata; $1^{\circ}$ Tesoureira: Dra. Virgínia Paes Lema Ferriani; $2^{\circ}$ Tesoureiro: Dr. Luiz Gonzaga Tone; $1^{\circ}$ Secretária: Dra. Lívia Carvalho Galvão; $2^{\circ}$ Secretária: Dra. Heloisa Bettiol

\section{AS ESPECIALIZAÇÕES NO DEPARTA- MENTO - BOLSAS DE ESTUDO}

O Prof. Woiski sempre se dedicou à Pediatria Geral e à Puericultura. Seu interesse indisfarçável pela clínica pode ser destacado por quadro muito comum dentro do hospital: o de sempre estar nas enfermarias e nos ambulatórios com seu estetoscópio na mão, pron- to para auscultar uma criança. E freqüentemente estava auscultando. Assim, na Pediátrica, seu interesse era pela clínica e, dentro desta, dedicava-se, especialmente, ao estado nutritivo das crianças e, nas discussões que fazia nos ambulatórios, nas enfermarias e nas discussões clínicas e clinicopatológicas, examinava com detalhes a nutrição e os aspectos metabólicos, relacionados com o caso. Nessas questões, quando discutia, dava ênfase ao aspecto prático. Em suas viagens de estudo, no início da carreira, nas décadas de 40 e 50, teve oportunidade de trabalhar com professores importantes como Joseph Stokes, da Universidade da Pennsylvania, com Paul Gyorgy e com Benjamin Krammer, nos Estados Unidos e com o Stanley Graham da Universidade de Glasgow. Aqui no Brasil, a alta frequência de desnutrição aguda e crônica das nossas crianças, na década de 60 , tanto nos ambulatórios como nas enfermarias, o levaram, definitivamente, para a área da nutrição e do metabolismo. A tese que apresentou ao concurso para a cátedra de Pediatria da FMRP-USP foi sobre nutrição e metabolismo. Deixava, porém, seus assistentes inteiramente livres para definirem suas áreas de estudo e pesquisa. Em 1985, publica a $1^{\mathrm{a}}$ ediçãodo livro de sua autoria, Nutrição e Dietética em Pediatria. Escreveu vários capítulos para o livro, mas convidou, também, os docentes do departamento para escreverem sobre as questões de nutrição que estudavam. O livro está, agora, em sua $5^{\text {a }}$ edição.

Evidentemente, há relação entre as bolsas de estudo e os interesses científicos dos docentes. Assim, a maioria das especializações se desenvolveram, no próprio Departamento de Pediatria ou em outros departamentos da Faculdade de Medicina e muitas foram aprimoradas no exterior, com bolsas de estudo, em centros avançados, das especialidades de interesse. Por tal razão, as bolsas de estudo são muito importantes ao desenvolvimento científico dos docentes e também à pós-graduação.

O primeiro docente do Departamento de Pediatria a viajar para o exterior com bolsa de estudo foi Olívio Paulus Junior, em 1959, durante 1 ano, em serviço de Nefrologia, nos Estados Unidos. Mas o Dr. Olívio desligou-se do Departamento no início da década de 60.

- Em 1961, Carlos Elyseo Castro Corrêa, nomeado em 1960, estagiou em Paris, no Hospital Netter, Serviço de Doenças do Metabolismo na Infância, sob a direção do Prof. Pierre Royer. O Dr. Carlos, entretanto, permaneceu pouco tempo, depois que voltou da viagem. Solicitou demissão e foi para 
Catanduva, ligando-se à Faculdade de Medicina de lá onde está até hoje.

- Em 1962, Sylvia Evelyn Hering, nomeada em 1962, viaja para a Suíça para estagiar durante 2 anos, realizando trabalho de investigação de laboratório em Enzimologia e Metabolismo de Ácidos Graxos, com o Prof. Ettore Rossi.

- Em 1967, Luiz Gonzaga Faggioni, nomeado em 1962, vai para a Inglaterra, por 1 ano.

- No final de 1973, José Romano Santoro, nomeado em 1962, vai para San Diego, Califórnia, USA, trabalhar em Pediatria Social na Universidade da Califórnia sob a direção do Prof. William Nyhan.

- Em 1971, Marco Antônio Barbieri, nomeado em 1970, faz, durante 3 meses, o Cours de Pediatrie Sociale, em Paris, com a Dra. Nathalie Masse; em 1978 faz, durante 9 meses, o Cours in Mother and Child Health, na Universidade de Londres e, em 1978, durante 1 ano e 5 meses, na mesma universidade, pesquisa sobre Estudo EpidemiológicoSocial da Saúde Materno-Infantil com os Profs. Tanner e Ebrahim.

- Em 1973, Rubens Garcia Ricco, nomeado em 1975, faz curso de Pediatria Social promovido pelo Centre Internationale de L'Enfance, na França e Hungria, durante 3 meses e, depois, em 1980, obtém estágio de pós-doutorado, na Inglaterra, com o Prof. John C. Waterlow, no Department of Human Nutrition of London School of Hygiene and Tropical Medicine.

- Em 1978, Salim Moysés Jorge, nomeado em 1970, durante 1 ano, faz pesquisa no Department of Royal Hospital for Sick Children, em Glasgow, na Escócia com o Prof. Forrester Cockburn. A pesquisa que desenvolveu foi sobre Insulin and Parenteral Nutrition in Preterm Babies. O interesse estava ligado à Neonatologia. O Prof. Salim e o Prof. Arthur, colegas de turma, continuaram, no departamento o estudo, a investigação em Nutrição em Neonatologia e deram a necessária continuidade no desenvolvimento da especialidade. Tiveram oportunidade de formar vários especialistas, muitos dos quais estão hoje no departamento ou em outras faculdades de Medicina, como docentes.

- Em 1979, Arthur Lopes Gonçalves, nomeado em 1970, faz curso na Bristol Maternity Hospital, da Universidade de Bristol, Inglaterra, com o Prof. Peter Dunn e Peter Fleming. Desenvolve trabalho de pesquisa sobre Estudo do controle da respiração em neonatos a termo e pré-termo.
- Em 1979, Paulo Benedito Franco, nomeado em 1972, faz na Faculdade de Medicina René Descartes, curso de Nefrologia Pediátrica, no Hospital Necker Enfants-Malades, Universidade de Paris. Desenvolve, no departamento a especialidade de Nefrologia.

- Em 1982, João Antônio Granzotti, nomeado em 1972, faz estágio de 1 ano na Division of Cardiology, da Universidade de Ilinois, de Chicago, nos Estados Unidos com o Prof. Hastreiter, tornando-se responsável pelo setor de Cardiologia Infantil.

- Em 1985, Francisco Eulógio Martinez, nomeado em 1981, faz estágio de 1 ano na Divisão de Nutrição, do Department of Nutrition and Family Economics, University of Britsh Columbia, Vanouver, Canadá, com o Prof. Indragid D. Desai. Desenvolveu pesquisa sobre Effects of ultrasonic homogenization on human milk. Volta ao mesmo serviço em 1989, por mais 3 meses. Em 1998, faz estágio no Departamento de Pediatria da Universidade de Calgary. Faz Neonatologia.

- Em 1990, Marisa Márcia Mussi Pinhata, nomeada em 1986, faz estágio de 1 ano na Division of Pediatric Immunology and Infeccious Deseases, Department of Pediatrics, University of Miami School of Medicine, Miami, USA, com o Dr. Gwendolyn Scott. Desenvolve o estudo de doenças infecciosas que comprometem o feto e o recém-nascido.

- Em 1991, Virgínia Paes Leme Ferriani, nomeada em 1987, faz estágio de 1 ano e 8 meses na Molecular Immunopathology Unit, Molecular Research Centre, Cambridge University, Cambridge. Foi seu projeto de pesquisa: Determination of on active site on the CD59 molecule responsible for binding to the complex C5b-9 com o Prof. J. Lachmann. É responsável pelo setor de Imunologia, Alergia e Reumatologia e Doenças Imunes.

- Em 1988, Luiz Gonzaga Tone, nomeado em 1977, fez estágio de 2 meses na Kyoto Prefectural University of Medicine, Department of Pediatrics, Japão, tendo como orientador o Prof. Shinsaku Imashuku. Volta mais duas vezes ao Japão para estágios. O primeiro no Saitama Câncer Center, em 1990, por 3 meses, para treinamento em Cytogenetics in hematological malignancy and solid tumors, com o Prof. Massaharu Sakurai. O segundo, em 1993, 1 mês, na Kyoto Prefectural University of Medicine, para Training Course of Researcher of Japanese Descendants in Biological and Cytogenetic Studies on Childhood Tumor com o Prof. Shinsaku 
Imashuku, Japão. O Prof. Tone, ao ser nomeado, iniciou o desenvolvimento da Hematologia, mas, logo, demonstrou interesse acentuado pela Oncologia, justificando as viagens que fez.

- Em 1990, Maria Célia Cervi, nomeada em 1986, faz estágio de 1 ano no Pediatric Research Center, Schneider Childrens Hospital, University of New York, USA. Desenvolveu pesquisa sobre Bactericidal Activity of Sera against a BPF com o Dr. Lorry Rubin. É responsável pelo Setor de Moléstias Infecciosas do Departamento.

- Em 1997, Heloisa Bettiol, nomeada em 1988, faz estágio de 1 ano no Department of Public Health Sciences, The Guy's King's College and St. Thomas Hospitals Medical and Dental School, University of London, Londres, Inglaterra, com o Prof. Roberto Roma. Desenvolveu pesquisa sobre Estudo epidemiológico-social da saúde perinatal e de escolares e adolescentes em Ribeirão Preto, SP, Brasil.

- Em 1997, Lívia Carvalho Galvão, nomeada em 1990, durante 1 mês, faz estágio no Serviço de Gastroenterologia Pediátrica da Universidade Degli Studi Di Napo Federico II, em Napoli, Itália, com o Prof. Ricardo Troncone. Antes, em 1987, durante 9 meses, estagiou, com bolsa de pós-doutorado, na Unidade de Gastroenterologia y Nutrición da Clinica Infantil de La Paz, da Universidade Autonoma de Madri, Espanha, com o Prof. Carlos Vasquez.

- A Dra. Lívia, formada em 1968 pela Faculdade de Medicina da Universidade Federal do Rio Grande do Norte, em Natal, foi bolsista da Macy, em 1969 e 1970, em nosso departamento e, depois, deu continuidade, fazendo pós-graduação nos níveis de mestrado e doutorado, tendo como orientador o Prof. Edgard Ferro Collares, formado em nossa Faculdade em 1964, tornou-se docente após a residência em Pediatria.Foi o iniciador da Gastroenterologia no Departamento.Estagiou durante 1 ano na Espanha, com o Prof. Balabriga. Manteve, por vários anos, sua disciplina em nosso Curso de Pósgraduação, formando vários pós-graduandos em nível de mestrado e doutorado. Já há alguns anos, o Prof. Collares transferiu-se para Campinas, sendo Titular de Pediatria na UNICAMP.

- Outros docentes desenvolveram especialidades em nosso departamento dentro do Programa de Pósgraduação em Nível de Mestrado e Doutorado: O Dr. Júlio Cesar Daneluzzi, nomeado em 1970, orientado pelo Prof. Woiski, faz Pediatria Social. É di- retor do Centro Médico Social Comunitário de Vila Lobato desde sua criação, em 1969. Está ligado ao programa de Medicina da Família, recentemente criado; a Dra. Maria Lúcia Silveira Ferlin, nomeada em 1978, orientada pelo Prof. Arthur Lopes Gonçalves em nível de mestrado e pelo Prof. Salim Moysés Jorge em nível de doutorado, faz Neonatologia; a Dra. Palmira Cuppo, nomeada em 1978, orientada pela Profa. Sylvia Evelyn Hering em nível de mestrado e doutorado, trabalha na Unidade de Emergência, em emergências pediátricas e na área de Toxicologia.

- Dos docentes da Pediatria, apenas dois passaram do regime de tempo integral para o de tempo parcial e desenvolvem clínica privada além do trabalho docente-assistencial na Pediatria. São eles: O Prof. Naul Mota de Souza, nomeado em1973, fez pósgraduação em nível de mestrado e doutorado com a Profa. Sylvia Evelyn Hering e se dedica à Pediatria Geral e à Nutrição e o Prof. Fernando Carlos Soares, nomeado, também, em 1973, fez pós-graduação em nível de mestrado e doutorado com o Prof. Collares, e, logo em seguida, se dedicou à Pediatria Psicossomática.

Mantendo-se dentro dos princípios básicos de sua criação, a diferenciação dos seus docentes, influenciada pelos pós-doutorados no exterior, principalmente, levou ao desenvolvimento de serviços em subespecialidades dentro da Pediatria, com os respectivos ambulatórios e leitos nas enfermarias do Hospital das Clínicas - Campus.

O ambulatório de Puericultura foi mantido, agregando-se a ele o acompanhamento de crianças com problemas de crescimento e de crianças e adolescentes com obesidade. A ação interdisciplinar e multiprofissional de apoio à atenção integral à criança e à sua família.

Outros ambulatórios de subespecialidades foram sendo criados ou tiveram seqüência.

\section{AMBULATÓRIOS DO HOSPITAL DAS CLINICAS - CAMPUS}

São os seguintes:

- Pronto Atendimento;

- Puericultura;

- Crescimento e Obesidade;

- Gastroenterologia Pediátrica e Nutrição;

- Hematologia e Oncologia;

- Nefrologia;

- Cardiologia; 
- Moléstias Infecciosas;

- Endocrinologia;

- Neonatologia: muito baixo peso, displasia pulmonar e geral;

- Psicossomática;

- Alergia, Reumatologia e Imunodeficiências - Pneumologia

Como suporte às atividades ambulatoriais, todas as subespecialidades contam com leitos nas enfermarias do Departamento de Pediatria - Hospital das Clínicas, Campus.

\section{CIRURGia PEDIÁtrica}

Um docente do Departamento de Cirurgia, depois de cumprir dois anos como residente de Pediatria, dedicou-se à cirurgia pediátrica e vem, assim, prestando valioso apoio à Pediatria, aos pacientes cirúrgicos. O serviço já conta com outros cirurgiões pediátricos.

\section{ENFERMARIAS DE PEDIATRIA DO HOS- PITAL DAS CLÍNICAS - CAMPUS.}

Estão localizadas no $7^{\circ}$ andar, com 39 leitos, distribuídos entre as especialidades:

- Gastrenterologia;

- Alergia, Imunologia e Reumatologia;

- Pneumologia;

- Endocrinologia;

- Cardiologia;

- Nefrologia;

- Hematologia e Oncologia;

\section{A UNIDADE DE TRATAMENTO INTEN- SIVO}

CTI - Pediátrico, com 6 leitos.

A CTI Neonatal, com 16 leitos.

Enfermarias do Berçário, no $8^{\circ}$ andar e as Enfermarias de recém-nascidos de médio e baixo risco, com 28 leitos.

O Alojamento Conjunto de mães e recém-nascidos, que foi implantado no início da década de 70 e tem sido mantido, conta com 20 leitos, também no $8^{\circ}$ andar.

O total de leitos que, no início do Departamento de Pediatria no Hospital das Clínicas, eram 28 hoje, atinge 100 leitos, sem contar os leitos das outras unidades.

\section{UNIDADE DE EMERGÊNCIA}

Foi instalada no antigo prédio do Hospital das Clínicas. A Pediatria conta com as seguintes áreas e serviços:

- Ambulatório de Emergência;

- Enfermaria de Pediatria, com 28 leitos;

- Enfermaria de Moléstias Infecciosas, com 9 leitos;

- CTI Pediátrica, com 6 leitos;

- Serviço de Atendimento a pacientes intoxicados;

- MATER - Maternidade do Complexo Aeroporto Está situada no Bairro Quintino Facci II, de Ribeirão Preto, com 40 leitos, no sistema de alojamento conjunto, atendendo a recém-nascidos a termo, de baixo risco.

Hoje, o Departamento de Pediatria é responsável por Disciplinas do $3^{\circ}$ ao $6^{\circ}$ ano da Graduação do Curso de Ciências Médicas, que incluem mais de 1300 h da carga horária do currículo médico. Os seus docentes participam ainda das disciplinas coordenadas pela Comissão de Graduação da FMRP-USP, como a de Iniciação à Saúde.

Destaque especial deve ser dado ao programa de treinamento dos médicos recém-formados que desejam se dedicar à Pediatria através da Residência Médica. Todos os anos há 24 residentes de $1^{\circ}$ ano, 24 de $2^{\circ}$ ano e $16-24$ de $3^{\circ}$ ano, nas subespecialidades.

É justo dizer que o desenvolvimento científico e tecnológico dos docentes do Departamento de Pediatria tornaram o citado serviço centro de referência regional e também nacional.

O Departamento de Pediatria, tanto no Hospital das Clínicas - Campus - como na Unidade de Emergência - cidade - atua em todos os níveis de atendimento, desde o primário ao terciário. O Serviço de Gastroenterologia Pediátrica participa do Grupo de Transplante Hepático; o de Nefrologia Pediátrica participa dos transplantes renais e o Serviço de Hematologia e Oncologia participa dos transplantes de medula óssea. É o Departamento de Pediatria participando na fronteira do conhecimento da promoção da saúde à recuperação dos comprometidos pelas doenças que levam a incapacidades.

Do início do Departamento, em 1956, até o presente, pode-se dizer que o desenvolvimento foi continuado e expressivo, como sempre desejou o Professor Woiski, isto é, estender a Pediatria e consolidá-la como disciplina básica do curso médico, sem descurar das especializações. 


\section{PROFESSOR JACOB RENATO WOISKI}

Neste relato histórico, onde estão destacados fatos memoráveis da vida do Departamento de Puericultura e Pediatria da FMRP-USP, é justo incluir a descrição simples, sem retoques, da figura marcante que foi o professor Woiski em nossa faculdade. Como ele era visto? Como era sentida a sua presença? Como ele reagia ou se manifestava em reuniões científicas e sociais?

Em 1983, ao ensejo dos 50 anos de sua formatura pela Faculdade de Medicina da Praia Vermelha, do Rio de Janeiro, o Prof. Woiski foi homenageado pelo Departamento de Pediatria da Faculdade de Medicina de Ribeirão Preto. O Prof. Santoro, em sua saudação,procurou descrever o Prof. Woiski e, de certo modo, dando as respostas às indagações há pouco feitas. Disse o Prof. Santoro: "Poderá parecer presunção, mas não considero difícil fazer o perfil do Prof. Woiski devido a um traço característico de sua personalidade: a espontaneidade de todas as suas atitudes. Sempre mostrou claramente como age, como pensa, como interpreta, sem deixar dúvida. Não usa meias palavras nem o sentido figurado. Fala o que pensa, é o que é".E continua: "Sempre considerou a assistência à criança em seu sentido mais amplo e mais puro. Nesta mesma linha, considerava o ensino da Pediatria. Por isso, sempre exigiu muita seriedade do estudante e dos que com ele trabalhavam. Não admitia certas falhas. Nessas ocasiões era enérgico. Outra característica importante é que confiava nas pessoas, indistintamente. Por esta razão, teve decepções. Não modificou, entretanto, sua conduta. Ainda hoje é assim".

"Outra particularidade é ser emotivo. Comovese diante de uma criança muito doente; comove-se ao ouvir o agradecimento de um pai, de um ex-aluno que venceu, de um seu assistente que está subindo degraus na carreira universitária. Seus ex-alunos, exresidentes, seus auxiliares o conhecem bem. Sabem que confia, que se emociona, mas que pode se exaltar diante de falhas".

"Este é um momento de lembranças", diz o Prof. Santoro. "Vale a pena continuar um pouco mais para relembrar fatos simples mas que fazem parte, também, deste perfil do Prof. Woiski e estão incluídos na história da nossa Pediatria, como por exemplo, as visitas rotineiras, de todas as manhãs, às enfermarias. De estetoscópio na mão, queria ver criança por criança, história por história, evolução por evolução, conduta por conduta. Nada superficial. Com ampla expe-

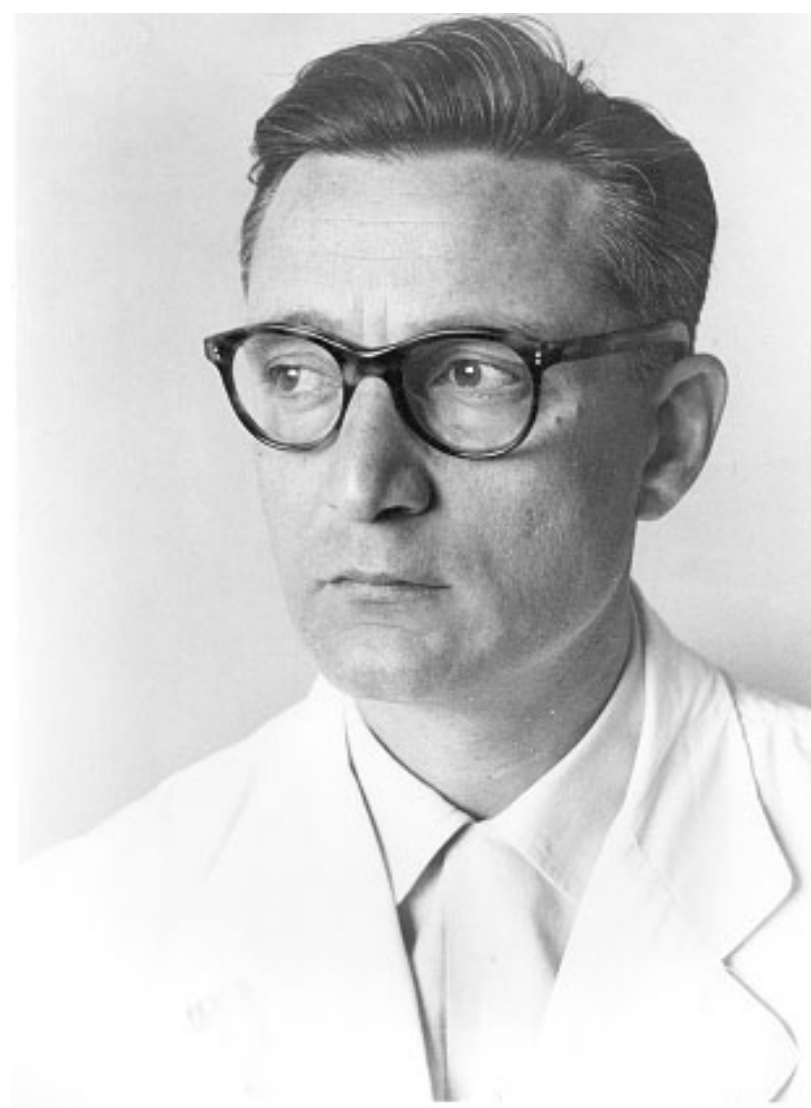

riência clínica, facilmente analisava os dados apresentados e dizia os por quês. Mas antes queria saber a opinião de todos a respeito. E aí é que, muitas vezes, a reunião se tornava tensa ou muito tensa".

"Participava de toda a vida do Departamento. Freqüentava as enfermarias, atendia e discutia nos ambulatórios e estava presente em todas as reuniões. Discutia, comentava utilizando sua experiência, sua observação e prática".

O Prof. Woiski gostava muito de nossa faculdade onde chegou a ser suplente de diretor e, também, diretor do Hospital das Clínicas. Mas, particularmente, gostava da Pediatria. Embora residindo em São Paulo, vinha com freqüência a Ribeirão Preto onde, por duas vezes, procurou residir novamente.

Mas, em conversas aqui ou em São Paulo, depois de aposentado, falava como se aqui morasse e aqui trabalhasse. Referia-se ao nosso Departamento de Pediatria como se aqui estivesse ainda, em plena atividade. Nas visitas que aqui fazia ao serviço, demonstrava querer ajudar e ajudava além de fazer sugestões de mudanças. 
Deixando Ribeirão Preto ao se aposentar, foi para São Paulo e assumiu lá, em 1972, a chefia do Departamento de Pediatria da Faculdade de Medicina da Santa Casa de São Paulo, onde permaneceu durante 8 anos e chegou a ser, também, diretor da mesma faculdade. De São Paulo foi para Taubaté para chefiar a Pediatria da Faculdade daquela cidade por pouco tempo.

O Prof. Santoro termina sua saudação em homenagem ao jubileu de formatura do Prof. Woiski dizendo o seguinte: "Pessoas como o Prof. Woiski que não param nunca, que sempre estão inovando e procurando solução para os problemas de saúde da criança e para o ensino são importantes para a nossa sociedade e para o mundo. São pessoas que lutam toda a vida e por isso são imprescindíveis".

\section{VISITAS DE PROFESSORES E PESQUI- SADORES}

- Prof. Lytt Gardner, da State University of New York, maio de 1967, proferindo palestra sobre Citogenética Humana e Síndrome de Privação Materna;

- Prof. Angel Ballabriga, de Barcelona, Espanha, em outubro de 1967, proferindo palestra sobre Síndrome de Dificuldade Respiratória no Recém-nascido;

- Prof. J. C. Waterlow, do Tropical Metabolism Research, da University of West Indies, Jamaica, agosto de 1968;

- Prof. Bo Vahlquist, diretor do Departamento de Pediatria da Universidade de Upsala, Suécia, junho de 1971, proferindo palestra sobre o ensino médico na Suécia;

- Dr. John Z. Bowers, President da Josiah Macy Jr Foundation, de New York, firmando convênio para treinamento de residentes em Pediatria, novembro de 1971;
- Dra. Irene Cid Schenberg, Delegada Federal da Criança em São Paulo, em visita ao Centro Médico Social Comunitário de Vila Lobato, em 1971, falando sobre a Campanha Educativa da Coordenação de Proteção Materno Infantil - Clube de Mães;

- Prof. V. Veenecklaus, Prof. de Pediatria da Faculdade de Medicina de Leiden, Holanda, dezembro de 1971, como membro da Organização Mundial da Saúde para visitar os centros comunitários de atendimento;

- Dra. Nicole Marie, Chefe do Setor de Antropologia do Serviço de Anatomopatologia Animal de Paris, França, agosto de 1972;

- Prof. G. G. Arneil, professor de Pediatria da Universidade de Glasgow, Escócia, setembro de 973;

- Dr. Carlos Serrano, da Organização Panamericana de Saúde, em visita aos Centros Comunitários, em abril de 1974;

- Dr. Angel Cordano do Laboratório Mead Johnson, Estados Unidos, fevereiro de 1975;

- Prof. J.M. Tanner, professor do Instituto of Child Health, da Universidade de Londres, junho de 1977, falando sobre Crescimento da Criança;

- Prof. Bernece Tanner, do Serviço de Saúde da Inglaterra, junho de 1977, falando sobre Atenção Médica na Inglaterra;

- Dra. Mia Pereira da Silva, do Museu Nacional de História Natural, de Paris, França, falando sobre Antropometria, em 1977;

- Prof. Peter M. Dunn, perinatologista da Universidade de Bristol, Inglaterra, outubro de 1989;

- Andrew W. Duncan, Radiologista Pediátrico do Royal Hospital of Sick Children, Bristol, Inglaterra, outubro de 1990;

- Prof. Peter Jeremt Berry, Patologista Pediátrico da Universidade de Bristol, Inglaterra, novembro de 1990. 